\title{
Impacts of Diversity and Inclusion Initiatives in a Civil and Environmental Engineering Department
}

\section{Mr. Tiago R Forin, Rowan University}

Tiago Forin is a $\mathrm{PhD}$ candidate in Engineering Education and researcher at Purdue University affiliated with XRoads Research Group, the Global Engineering Program and the Office of Institutional Research, Assessment, and Effectiveness. He received a Bachelor's degree in civil engineering from Florida State University and a Master's degree in environmental engineering from Purdue University.

\section{Dr. Stephanie Farrell, Rowan University}

Dr. Stephanie Farrell is Interim Dean of the College of Engineering and Professor and Founding Chair of Experiential Engineering Education at Rowan University (USA). Dr. Farrell has contributed to engineering education through her work in inductive pedagogy, spatial skills, and inclusion and diversity. She has been honored by the American Society of Engineering Education with several teaching awards such as the 2004 National Outstanding Teaching Medal and the 2005 Quinn Award for experiential learning, and she was 2014-15 Fulbright Scholar in Engineering Education at Dublin Institute of Technology (Ireland).

\section{Dr. Kauser Jahan P.E., Rowan University}

Kauser Jahan, is a Professor of Civil and Environmental Engineering at Rowan University. She received her B.S.C.E. from the Bangladesh University of Engineering and Technology, an MSCE from the University of Arkansas, Fayetteville and a Ph.D. from the University of Minnesota, Minneapolis. Her passion as an educator and mentor has been recognized by many professional organizations over the years. She is the recipient of the Gloucester County Women of Achievement Award, Lindback Foundation Teaching Award, the NJ ASCE Educator of the Year award, the Gary J. Hunter Excellence in Mentoring Award, the ASEE Environmental Engineering Division Meritorious Service Award, the ASEE Women in Engineering Division Sharon A. Keillor Award and the WEPAN Women in Engineering Initiative Award. She has been instrumental in establishing the Attracting Women into Engineering, the Engineers on Wheels and Engineering Clinics for Teachers programs at Rowan University. She has served as the Institutional Representative and Advisory Board Chair for the Women's Professional Network at Rowan University for six years and currently is an advisory board member of the New Jersey Chapter of the American Council on Education (ACE) Office of Women in Higher Education (OWHE). She received a Fulbright award in 2015.

\section{Stephanie Lezotte, Rowan University}

Stephanie is a Ph.D. candidate studying postsecondary and higher education. Using organizational theories, she examines systems and structures that contribute to the oppression and symbolic violence of minoritized and underrepresented students. Her dissertation focuses on institutional messages about diversity and inclusion in engineering.

\section{Dr. Beena Sukumaran, Rowan University}

Beena Sukumaran has been on the faculty at Rowan University since 1998 and is currently Professor of Civil and Environmental Engineering. She is currently serving as Vice President for Research. Her area of expertise is in micro-geomechanics and has published over 100 peer reviewed conference and journal papers including several papers on engineering education and the unique undergraduate curriculum at Rowan University, especially the Engineering Clinics. She has been involved in various outreach activities to recruit more women and minorities into engineering and has served as Division Chair of the Women in Engineering Division. She is the recipient of the 2011 New Jersey Section of ASCE Educator of the Year award as well as the 2013 Distinguished Engineering Award from the New Jersey Alliance for Action.

\section{Prof. Harriet Hartman, Rowan University}


Professor of Sociology, Chair of Sociology and Anthropology Department, Rowan University. Co-p.i. of RED NSF RevED project at Rowan University. Editor-in-chief, Contemporary Jewry.

\section{Dr. Ralph Alan Dusseau P.E., Rowan University}

Dr. Ralph Dusseau is a Professor of Civil and Environmental Engineering at Rowan University in Glassboro, New Jersey. Dr. Dusseau is also serving as the Associate Chair of the Department of Civil and Environmental Engineering and is Coordinator of the Engineering Management Programs at Rowan University. Dr. Dusseau was an Assistant and Associate Professor at Wayne State University in Detroit, Michigan from 1985 to 1995 . Dr. Dusseau was the Founding Chair of the Department of Civil and Environmental Engineering at Rowan University from 1995 to 2008.

\section{Theresa FS Bruckerhoff, Curriculum Research \& Evaluation, Inc.}

Theresa Bruckerhoff is the Principal Research Associate and Operations Manager at CRE., with nearly twenty-five years of evaluation experience, ten years as the principal evaluator. She studies and evaluates training, professional development and other education change programs funded by state, federal and private sources and is a member of the American Evaluation Association, ASEE, and other content and education focused professional organizations.

\section{Dr. Sarah K. Bauer, Rowan University}

Dr. Sarah Bauer is an Assistant Professor in the Department of Civil and Environmental Engineering at Rowan University. Dr. Bauer holds a doctoral degree in Civil and Environmental Engineering from the University of Virginia, Charlottesville. Dr. Bauer is the recipient of numerous awards and scholarships as a young professional. Her primary research interests are: water and wastewater treatment, renewable energy technologies, and pollution prevention. She has worked on a variety of educational projects to enhance environmental engineering education while at Rowan University. Dr. Bauer is an active member of ASEE and the Society of Women Engineers (SWE) and currently serves as the Faculty Advisor for Rowan's Student Chapter of SWE. 


\title{
Impacts of Diversity and Inclusion Initiatives in a Civil and Environmental Engineering Department
}

\begin{abstract}
In 2016, the Civil and Environmental Engineering (CEE) Department at Rowan University was awarded a Revolutionizing Engineering Departments (RED) grant from the National Science Foundation. The goal for the RED grant was to allow institutions to improve the inclusion of minorities over the course of five years through changes in curriculum, policy, institutional structure, and institutional culture. The CEE Department used this opportunity to establish a research group who would focus on helping underrepresented and underserved populations of students through an institutional means. The researchers sought out a variety of ways to enable inclusive practices within the CEE Department and the greater institution. Surveys and interviews were conducted to include faculty and student perspectives to address inclusivity, workshops were held to help faculty understand examples of inclusive practices inclusive practices, and partnerships with other campus offices helped with making policy changes that would affect the department and the institution at large. Currently, the researchers are in the fourth year of the grant. The CEE Department has undergone evaluation of what impacts can be felt by students and student interviews have occurred that allow the researchers to gain first hand student insight for what the climate of diversity is like for them. As in previous years, this poster intends to show a variety of the developments made by the researchers and the CEE Department. The poster will feature information on the changing student demographics, student perception of the climate of diversity, the impact evaluations of the CEE Department's efforts and an overview of larger institution wide efforts being made to positively impact the entire engineering college and university. As the grant enters its final years, the poster will also discuss plans on engaging the broader engineering academic community in order to establish best practices for implementing diversity and inclusion initiatives in other programs.
\end{abstract}

\section{Introduction}

Rowan University's Civil and Environmental Engineering (CEE) Department was awarded the National Science Foundation's Revolutionizing Engineering and computer science Departments (RED) grant back in 2016. The purpose of the grant is to change the department's ability to serve underrepresented minorities (URMs) and underserved groups over the course of the next five years. The grant provides funding over those five years to support the CEE Department's initiatives. These initiatives include curriculum changes, faculty development, mentoring, and changes in admissions. The initiatives taken by the researchers are influenced by critical education theory which is a framework that utilizes practices in education that enable social transformation in students where equity is developed for all students [1]. The research team involved in the RED grant represents a multidisciplinary personnel with backgrounds in civil and environmental engineering, engineering education, higher education, and sociology. Currently the RED grant is in the fourth year of its lifespan. This year, the researchers added considerable focus to initiating changes beyond the department to the greater institution. 
Since the beginning of the RED grant, the CEE Department provided faculty multiple opportunities to help develop a climate of inclusion for students. The CEE Department recognized that this was essential to its future success. Prior to the start of the RED grant, the representation of women enrolled in the CEE Department was slightly below 20\%, which was below the current national average of women in CEE as reported by the National Academy of Engineering [2]. The representation of URM students in the CEE Department was less than 10\% of the student population which is also below the average reported by the NAE [2]. The CEE Department saw this the RED grant as an opportunity to directly address these issues. While URMs can include diversity in sex, race and ethnicity, the CEE Department made a conscious decision to address all forms of visible and non-visible diversity. Nonvisible elements of diversity include socioeconomic status, ability, and sexual orientation, among others like being first-generation or being a nontraditional student. Since these aspects are non-visible, that also can be easily overlooked in education and are also harder to track within the student body [3]. Underserved groups like first-generation, transfer, and nontraditional students also are accounted for by the grant. As a result of the wide scope of this project, the researchers was very well aware that they would have to reach out to the larger institution in order to enable more effect change throughout campus and have made this a focal point for the final years of the grant.

First, Second, and Third Year Summary

The first year of the RED grant established a sense of what the climate of diversity was like within the university. A survey was given to form a baseline of what is the current state of diversity within the College of Engineering. This survey allowed students and faculty to identify how their coursework and daily school lives were focused on diversity and inclusion $[4,5]$. Students had expressed their concerns on the how diversity was perceived at the university and faculty also explained that they wished to know more about how to engage a more diverse student body. The baseline survey informed the researchers to take further steps with faculty. In order to help with faculty engagement, workshops were held to enable faculty to have conversations about diversity and develop plans for including more inclusive pedagogy in their courses [6]. The researchers also performed an initial analysis of SAT scores from students and found that some SAT scores were beneath the expected value but students were admitted anyway. This gave the researchers justification to engage the Office of Admissions in order to allow the CEE Department to take a holistic approach to accepting students. This holistic approach included incoming students' high school transcript, extracurricular activities and admissions essays. To further help incoming first-year and transfer students, peer mentoring programs were established to help connect students with good resources for improved retention [7].

For the second year, another survey was given only to CEE students. This was done to isolate any experiences and issues that were specific to CEE students. This survey was used to help the researchers justify a qualitative phase of data collection as they helped frame the interviews that would come in year three. The second year also saw the CEE faculty start making curricular changes. The curricular changes were based on critical pedagogy. The researchers chose this framework since enables faculty to see how certain voices and approaches are included and 
excluded in content development and it allows students to see how they can contribute to their own learning [8]. These changes made by the CEE faculty were not large in scope but they did utilize global topics as a means to initiate talks with students about diversity and inclusion. The reasoning behind using global examples was driven by work done by Donna Riley. Riley also utilizes critical pedagogy and mentions that non-western examples are a part of inclusive practice and the Accreditation Board for Engineering and Technology deems that students should have some level of global competence $[9,10]$. Global examples were seen as an effective way to discuss cultural differences with engineering students, since there are significant global projects and cases in civil and environmental engineering. The faculty developed numerous assignments, projects, and examples that covered the intersections of technical and social knowledge to help students see the implications of engineering on society [9]. The researchers was also able to bring multiple speaker panels where students learned about how diverse alumni worked in engineering and how to navigate their professional experience with diversity and inclusion as an essential part of the experience. The researchers also began their first foray into spreading intuitional change to a broader audience by developing their own webpage and social media accounts to share ideas on how to best change the climate of diversity at different institutions.

The third year of the RED grant began with a change in leadership and personnel but also with a focus in establishing more influence across the College of Engineering and the entire institution. The researchers increased collaboration with the Experiential Engineering Education (ExEEd) Department which is interested in developing engineering students for their first two years in the College of Engineering. In Spring of 2019, interviews were conducted with students to see how they perceived diversity and inclusion at the university. The analysis of these interviews would be a major point of development for the fourth year since they would help the researchers identify specific issues the students were facing and what specific inventions can be done on their behalf.

In the third year, students even have a chance to have their own input in the development of new content. A researcher began independent study courses that had students develop small assignments and classroom examples using a variety of engineering examples from around the world and even from the region of the country that the student body is most acquainted with. These students also looked at methods to engage visual learners in class since some students realized that they could also learn from visually driven content. The inclusion of students and allowing them to include their own lived experiences in their educational development is rooted in critical education theory as well $[8,9]$. Along with these student-developed content, the CEE Department also began surveying students on what impacts the previously developed global examples had on their understanding of engineering.

Another major climate survey was given to students and faculty to see if there had been positive changes since the baseline survey was initiated. The researchers connected with the Faculty Center for Excellence in Teaching and Learning on campus in the third year as a means to begin work on institutional changes for the university. The partnership with the Faculty Center would allow faculty to work on diversity and inclusive initiatives and get proper professional recognition for it in the form of a certificate. In the third year, the Faculty Center in partnership 
with the RED grant researchers tried to establish meetings with a variety of different stakeholders in the university to determine what would be an appropriate direction to ensure increased and permanent change at the institutional level.

\section{The Fourth Year}

The partnership between the Faculty Center and the researchers enabled the development of a faculty and staff certificate program with the Division of Diversity, Equity, and Inclusion that was established at the university in 2019. Two researchers on the RED grant serve on the committee to establish a workshop series that will educate faculty and staff on what inclusivity is and how to work towards the benefit of the student experience. Faculty and staff can obtain this certificate by going to a variety of workshops facilitated by the Faculty Center and the researchers. This certificate allows faculty and staff to catalogue professional development and acquisition of new skills for tenure and recontracting. As the certificate program grows, the ultimate goal would be that faculty would be trained enough to develop their own inclusive materials and even become advocates for diversity and inclusion. The first round of workshops was deployed this Spring semester and will inform the researchers about what improvements can be made for increasing the effectiveness of the workshops.

This year will also see yet another round of qualitative data collection with another round of student interviews. The first run of analysis of the first set of interviews showed that students have a keen awareness as to how certain groups of URMs have specific issues to overcome. In the initial analysis, some transfer students made remarks that made the researchers aware of some issues they were facing and how effective our transfer mentoring group was for helping students through their difficulties. The researchers will use this second round of interviews as a means to increase the amount of critical student voices. This allows the researchers to make a case for the students who feel overlooked and improve the quality of their education. As with previous years CEE faculty are still developing their own inclusive curriculum content. A researcher is running another round of student content development independent studies. There are students from outside the CEE Department that are taking the course and developing their own global discipline-specific examples. Once the new content is developed, conversations will occur with non-CEE faculty to see what can be realistically implemented in their courses. Another independent study managed by one of our researchers is also developing content to be used in exposing younger students to engineering before they reach college age. The CEE Department analyzed the results of surveys given to courses that utilized global examples in class and saw that the students were able to recognize the importance of understanding global issues in engineering. The surveys did reveal however that adjunct professors who did not use the content had students who saw less connections between engineering and global issues. These course surveys will continue to monitor how students are adjusting to the content that is being developed.

\section{Summary}

This paper offers a summary of all the current initiatives taking place with the RED research team for the 2019-2020 academic year. While the RED research team is more focused on wider 
institutional initiatives, the CEE focus will remain. Students are being offered to give their insights to the climate of diversity on campus through surveys and interviews. This will give the Researchers a clear direction into what new actions they can take. The CEE faculty are continuing with course development with inclusive activities and assessment that take into account multiple learning styles and the students' lived experience. A major development being undertaken in the project's fourth year will be the faculty certification process that will be distributed using the Faculty Center on campus. This certification process aims to establish a deeper institutional change that will all faculty to take credit for their inclusive endeavors for tenure and promotion. This will be the first attempt to bring significant change to the institution outside of the CEE department and to develop a network of eager allies from across the campus. The new initiatives will be the building block for a renewed focus on wider institutional change and will guide the research team for the remaining year of the grant.

Acknowledgments

This material is based upon work supported by the National Science Foundation under IUSE/PFE:RED Grant No. 1623053. Any opinions, findings, and conclusions or recommendations expressed in this material are those of the author(s) and do not necessarily reflect the views of the National Science Foundation.

References

1. T.S. Popkewitz and L. Fendler, Critical Theories in Education: Changing Terrains of Knowledge and Politics. Psychology Press, 1999.

2. P. Layne, "Diversity by Numbers," Leadership and Management in Engineering, vol 1 ed. (4), pp. 65-71. Oct, 2001.

3. D. Riley, A. Slaton, and A. L. Pawley, "Inclusion and Social Justice: Women and Minorities in Engineering." in Cambridge Handbook of Engineering Education

Research, A. Johri and B. Olds, Ed., Cambridge University Press 2014.

4. B.M. Ferdman, "The practice of inclusion in diverse organizations," in Diversity at work: The practice of inclusion, B. Ferdman and B. R. Deane, Ed. New York: Wiley 2014, pp 3-54.

5. R. Jost, Benchmarks for Cultural Change in Engineering Education. University of Newcastle, 2004.

6. T. Forin, B. Sukumaran, S. Farrell, H. Hartman, K. Jahan, R. Dusseau, P. Bhavsar, J. Hand, \& T. Bruckerhoff, "Rethinking Engineering Diversity, Transforming Engineering Diversity," ASEE Annual Conference \& Exposition, June 24-28, 2017, Columbus, Ohio. American Society for Engineering Education, 2017.

7. J. L. Mondisa, "Increasing diversity in higher education by examining African-American STEM mentors' mentoring approaches," 2015 International Conference on Interactive Collaborative Learning (ICL), Florence, 2015, pp. 321-326.

8. Freire, P. (2018). Pedagogy of the oppressed. Bloomsbury publishing USA.

9. D. Riley, "Pedagogies of liberation in an engineering thermodynamics class, " ASEE Annual Conference and Exposition, June 22-25, 2003, Nashville, Tennessee. American Society for Engineering Education, 2003. 
10. Accreditation Board for Engineering and Technology, "Criteria for Accrediting Engineering Programs 2018-2019," [Online]. Available:

http://www.abet.org/accreditation/accreditation-criteria/criteria-for-accreditingengineering-programs-2018-2019/\#program. [Accessed: January 30, 2019]. 